\title{
PLEOMORPHIC ADENOMA OF SOFT PALATE: A CASE REPORT
}

Mukesh S. Narwaria' ${ }^{1}$, Sunil Agrawal'2, Deepanshu Sharma ${ }^{3}$, Nikhil Chopra ${ }^{4}$

\section{HOW TO CITE THIS ARTICLE:}

Mukesh S. Narwaria, Sunil Agrawal, Deepanshu Sharma, Nikhil Chopra. "Pleomorphic Adenoma of Soft Palate: a Case Report". Journal of Evolution of Medical and Dental Sciences 2014; Vol. 3, Issue 18, May 05;

Page: 5009-5012, DOI: $10.14260 /$ jemds/2014/2545

ABSTRACT: Pleomorphic adenoma, also called benign mixed tumor, is the most common tumor of the salivary glands. About $90 \%$ of these tumors occur in the parotid gland and $10 \%$ of them occur in the minor salivary glands. The most common sites for pleomorphic adenoma of the minor salivary glands are the palate, followed by the lips and the cheeks. Other rare sites include the floor of the mouth, tongue, tonsil, pharynx, the retromolar area and the nasal cavity. Here, we are reporting a case of pleomorphic adenoma of the soft palate in a 45 year old Indian female. The mass was removed by wide local excision with adequate margins under GA.

KEYWORDS: Pleomorphic adenoma, minor salivary glands.

INTRODUCTION: Pleomorphic adenomas are benign salivary gland tumors that represent about 3$10 \%$ of the neoplasms of the head and neck region. ${ }^{1}$ They are the most common tumors $(50 \%)$ of the major and the minor salivary glands. ${ }^{2}$ The palate is considered as the most common intra-oral site (42.8-68.8\%), followed by the upper lip (10.1\%) and the cheeks (5.5\%).3,5 Other rare sites include the throat $(2.5 \%)$, the retromolar region $(0.7 \%)$, the floor of the mouth and the alveolar mucosa. ${ }^{[4]}$ Pleomorphic adenoma usually presents as a mobile, slowly growing, painless, firm swelling that does not cause ulceration of the overlying mucosa. ${ }^{6}$ Pleomorphic adenoma consists of cells with epithelial and mesenchymal differentiation (mixed tumor). The highly variable morphology of this neoplasm is the result of the interplay between these elements. Now, it has been widely accepted that both epithelial and mesenchymal (myxoid, hyaline, chondroid and osseous) elements often arise from the same cell clone, which may be a myoepithelial or a ductal reserve cell. Lee et al examined formalinfixed, paraffin-embedded tissues from 13 pleomorphic adenomas of female patients and the findings from them suggested that the stromal and epithelial cells in pleomorphic adenomas of the salivary gland arose from the same clone in most of the cases. ${ }^{7}$ The variants of pleomorphic adenoma include pleomorphic adenoma with a lipomatous change, myxolipomatous pleomorphic adenoma, pleomorphic adenoma with a squamous differentiation and benign metastasizing mixed tumour. ${ }^{8}$

CASE REPORT: A 45 year old female reported to the Department of Surgery with complaint of a nonpainful swelling over the soft palatal region since the last six months (Fig 1). The swelling was not interfering with mastication; there was no history of trauma or fever. The past medical history, the past dental history, the family history and the social history were not relevant. The patient had no history of tobacco chewing and cigarette smoking. On general examination, it was found that the patient was of normal build and height. His vital signs were normal and no abnormality was detected on his systemic examination. Extraorally, there was no facial asymmetry, and no evidence of any trauma. Nothing abnormal was detected on examination of the lymph nodes. His intra-oral examination revealed a single domed shaped swelling which approximately measured $3 \times 3 \mathrm{cms}$ over soft palate in midline [Fig-1]. The overlying mucosa was not ulcerated and it was mobile over the 
swelling. On palpation, the swelling was found to be firm in consistency, compressible and nontender. On the basis of the history and the clinical examination, a provisional diagnosis of benign tumor of the minor salivary gland was made and a differential diagnosis of malignant tumor of the minor salivary gland and lipoma was considered.

The radiograph of the maxilla (occlusal view) did not show any bony invasion. CT scan report revealed a homogenously enhancing, well defined hypodense lesion which measured $2.0 \times 2.3 \mathrm{cms}$ in the soft palate, with no bony invasion. A wide local excision with adequate margins was done under GA and the histopathological report of the biopsy specimen confirmed the diagnosis of pleomorphic adenoma (Fig 2).

DISCUSSION: Muco-epidermoid carcinoma is the most common malignant salivary gland tumor, while pleomorphic adenoma is its most common benign counterpart. The differential diagnosis for this case includes malignant tumor of the minor salivary gland and lipoma. Plain X-rays and hematologic investigations play no part in the diagnosis of salivary gland tumors of the palate. CT is superior to MRI in evaluating the erosion and the perforation of the bony palate, or the involvement of the nasal cavity or the maxillary sinus. MRI provides a better definition of the vertical and inferior tumor extension and it more accurately indicates the degree of encapsulation 9, 10. MRI is also advantageous because of the absence of the exposure to radiation and because of the intravenous contrast 1110 medium.

A histological diagnosis is essential to plan the definitive management. The treatment consists of wide local excision with clear margins which involves the periosteum and the associated mucosa, followed by curettage of the underlying bone with a curette or bur under copious, sterile, normal saline irrigation ${ }^{10}$. The overlying mucosa can sometimes be repaired by using a local flap. In our case, the patient did not require reconstruction as the palatal mucosa was regenerated and as there was no oro-antral fistula formation. Pleomorphic adenoma is encapsulated, and an incomplete excision can leave behind residual tumor cells, resulting in recurrence, because of its high rate of implantability.

CONCLUSION: This case represents a classic example of pleomorphic adenoma of soft palate. Successful treatment begins with an appropriate referral and a biopsy-proven diagnosis. Computed tomography aids in evaluating the extent of the lesion and in guiding the surgical strategy. A longterm follow-up is warranted because of the risk of recurrence even several years after the initial excision.

\section{REFERENCES:}

1. Garcia Berrocal JR, Ramirez Camacho R, Trinidad A, Salas C. Mixed tumour (pleomorphic adenoma) of the head and neck- Typical and atypical patterns. An Otorrinolaringol Ibero Am 2000; 27: 333-40.

2. Traiger J, Rosen MB. Mixed tumor of the cheek; report of a case. Oral Surg Oral Med Oral Pathol1965; 19:711-14.

3. Van Heerden WF, Raubenheimer EJ. Intra-oral salivary gland neoplasms: a retrospective study of seventy cases in an African population. Oral Surg Oral Med Oral Pathol1991; 71: 579-82.

4. Wang D, Li Y, He H, Liu L, Wu L, He Z. Intra-oral minor salivary gland tumors in a Chinese population: a retrospective study on 737 cases. Oral Surg Oral Med Oral Pathol Oral RadiolEndod2007; 104:94-100. 
5. Toida M, Shimokawa K, Makita H, Kato K, Kobayashi A, Kusunoki Y, et al. Intra-oral minor salivary gland tumors: a clinicopathological study of 82 cases. Int J Oral MaxillofacSurg2005; 34: 528-32.

6. Kaminski M, Janicki K. A case of giant pleomorphic adenoma of the cheek with two malignant centers. Otolaryngol Pol 2002; 56: 385-87.

7. Lee PS, Sabbath-Solitare M, Redondo TC, Ongcapin EH. Molecular evidence that the stromal and epithelial cells in pleomorphic adenomas of the salivary gland arise from the same origin: clonal analysis by using the human androgen receptor gene (HUMARA) assay. Hum Pathol2000; 31:498-503.

8. Kondo T. A case of lipomatous pleomorphic adenoma in the parotid gland. Diagn Pathol 2009; $4: 16$.

9. Rodríguez-Fernández J, Mateos-Micas M, Martínez-Tello FJ, Berjón J, Montalvo JJ, FortezaGonzález G, et al. Metastatic benign pleomorphic adenoma. Report of a case and review of the literature. Med Oral Patol Oral Cir Bucal.2008; 13:193-96.

10. Mubeen K., Vijayalakshmi K.R., Pati A.R et al. Benign pleomorphic adenoma of the minor salivary gland of the palate. Journal of Dentistry and Oral Hygiene. 2011; 3:6:82-88.

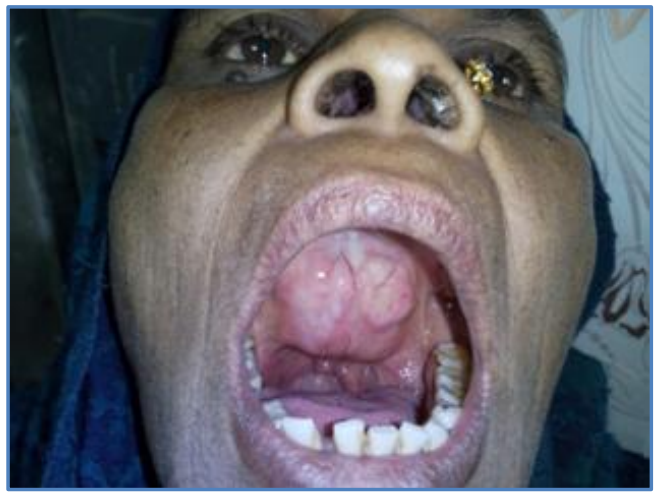

\section{Figure 1: Showing swelling over soft palate}

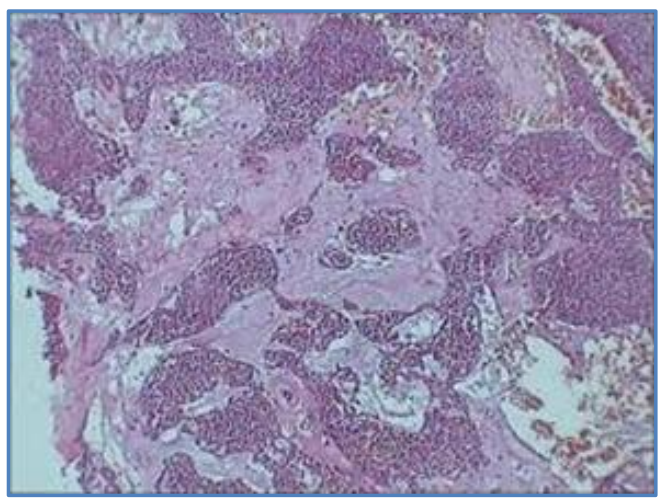

Figure 2: Showing histopathological slide of the excised mass 


\section{CASE REPORT}

\section{AUTHORS:}

1. Mukesh S. Narwaria

2. Sunil Agrawal

3. Deepanshu Sharma

4. Nikhil Chopra

\section{PARTICULARS OF CONTRIBUTORS:}

1. Assistant Professor, Department of General Surgery, Gajra Raja Medical College.

2. Associate Professor, Department of General Surgery, Gajra Raja Medical College.

3. Post Graduate Student, Department of General Surgery, Gajra Raja Medical College.

4. Post Graduate Student, Department of General Surgery, Gajra Raja Medical College.

\section{NAME ADDRESS EMAIL ID OF THE} CORRESPONDING AUTHOR:

Dr. Mukesh S. Narwaria, \#25, Rajya Karmchari Awas Nigam, Near Vivekanand Needum, Mahalgaon, Gwalior, M. P.

E-mail: narwariams@yahoo.co.uk

Date of Submission: 15/04/2014. Date of Peer Review: 16/04/2014. Date of Acceptance: 23/04/2014. Date of Publishing: 05/05/2014. 